\title{
Coptis Teeta: Conservation and Cultivation Practice - A Rare Medicinal Plant on Earth
}

\author{
Dhiman Mukherjee $^{* 1}$ and Soumendra Chakraborty ${ }^{2}$ \\ ${ }^{1}$ Department of Agronomy, Bidhan Chandra Krishi Viswavidayalaya, India \\ ${ }^{2}$ Departmement of Genetics and Plant Breeding, India
}

*Corresponding author: Dhiman Mukherjee, Department of Agronomy, Bidhan Chandra Krishi Viswavidayalaya, Directorate of Research, Kalyani-741235, West Bengal, India

\begin{abstract}
According to variation of climatic zones, medicinal plants vary for their occurrence in different hills. Some of the medicinal plants are distributed in high potential whereas certain others go on depleting from their natural habitat and leads to extinction such as Coptis teeta. This depletion is due to high pressure for their unsystematic exploitation through shifting cultivation expansion of urbanization, agricultural land and road development as well as some natural calamities like land sliding, etc. Cultivation of medicinal plants in the region have also been undertaken in large scale for acclimatization of plants growing in one part to other part accordingly. The present study was made for the cultivation and acclimatization of Coptis teeta in Darjeeling himalaya. This was possible through ex-situ conservation as well as undertaking cultivation by the local inhabitants in their own or community lands. This plant is bitter, cooling and a potent bacterostatic herb. The dried rhizomes of this plant contains major active compounds berberine and coptine and used as antidiabetic, bitter tonic, carminative, expectorant, febrifuge, ophthalmic and stomachic.

The present study was conducted from September, 2009 to August, 2012 under the aegis of Uttar Banga Krishi Viswavidyalay, Kalimpong, with a objective of cultivation and characterization of Coptis teeta in Darjeeling hills Our focus on present study was mostly confined to Lava (2200 m asl) region of Darjeeling. Our observation revealed that, this prefer sandy loam soil, high in organic carbon (0.73 to $1.03 \%$ ), available N (231.95 to $299.16 \mathrm{~kg} / \mathrm{ha}$ ), P2O5 (17.11 to $22.11 \mathrm{~kg} / \mathrm{ha}$ ) and K20 (186.19 to $273.11 \mathrm{~kg} / \mathrm{ha})$ content with $\mathrm{p}^{\mathrm{H}} 4.5$ to 5.6. It is propagated by rhizomes and seeds. This was a small, stemless perennial evergreen herbs. Rhizome oblique to horizontal with persistent fibrous roots, bitter, yellowish brown externally, golden-yellow internally. Plant height vary from 10 to $18 \mathrm{~cm}$. Petiole length differ from 7 to $14 \mathrm{~cm}$, and its depend on growing condition of plant. Rhizome length $(2.1$ to $4.9 \mathrm{~cm})$ and its weight ( 4.3 to $8.9 \mathrm{~g}$ ) depend on duration of crop. Leaves $4.5-9.3 \mathrm{~cm}$ long, lamina 3-lobed, pinnatifid and glabrous. Flower initiation and flowering period confined to mid of February to April, however it vary with land topographical situation.
\end{abstract}

Keywords: Cultivation; Conservation; Eastern Himalaya; Endangered Plant

\section{Introduction}

Since time immemorial Himalaya is famous for its rich medicinal and aromatic plant biodiversity. Plants provide people with food and medicine. The varying soil, topography and occurrence of different climatic and micro-climatic zones of the region provide very congenial conditions to grow a number of therapeutically important medicinal plant species. Nowadays due to increasing awareness towards herbal products there is tremendous pressure on Himalayan medicinal plants. In this region no serious attempts are made for commercial scale cultivation of these important plants, of high altitude areas. The unscientific, over and irregular exploitation of medicinal plants from its natural habitat has resulted in very fast depletion as well as extinction of some valuable herbal plant Chakraborty et al. [1]. Improved agro-technology of highly demanded medicinal plants and their commercial scale cultivation with improved cultivars are the need of the hour. The threat of extinction can be reduced by developing their agro-technology, adopting scientific methods of collection, in-situ and ex-situ conservation, etc. Mukherjee [2]. Biodiversity is the very foundation for all the Earth's essential goods and services. The air we breathe, water we drink, and the food we eat all depend on the Earth's rich biodiversity. Forty percent of all prescriptions written today are 
composed from the natural compounds found in different species. An estimated 80,000 edible plants are found in the world, and one in every three mouthfuls of the food you swallow is prepared from plants pollinated by wild insects and animals. Biological resources must be conserved if they are to continue supporting life on earth.

USAID supports biodiversity conservation principally through habitat conservation and supports limited speciesspecific conservation efforts as well. (Source: www.usaid.gov. in). Conservation of Coptis teeta is very important as it is one of valuable treasure of earth in the field of medicinal plant. This plant belongs to family: Ranunculaceae. Common name of this plant in world wide is Gold thread (Vernacular names: Assam. - Mishmi tita; Arabic - Mamira-chini; Hindi: Mamira; Sanskrit - Supita; Tam.: Pitarohini). As per various literature, this plant distributed in India (Arunachal Pradesh), China, Tibet and Nepal Huang and Long [3]. This plant is bitter, cooling and a potent bacterostatic herb. The dried rhizomes of this plant constitute the raw drug and contain major active compounds berberine and coptine. In action, the drug is antidiabetic, bitter tonic, carminative, expectorant, febrifuge, ophthalmic and stomachic. It is used for the treatment of various types of fevers, debility after fever, dysentery, nausea, jaundice, flatulence and visceral obstruction, haemorrhages (either from dysentery or from haemoptysis), conjunctivitis, nervous diseases, eye troubles, appetiser, constipation, indigestion, dyspepsia, asthma and cough. It is also reported to relieve toothache. It is a very much useful in malarial fever. It is used as general all-round tonic. Mostly in market, this plant becomes adulterated with various allied medicinal plant species. The rootstock of Geranium wallichianum D. Don ex Sweet (Geraniaceae) is used as a substitute for Coptis teeta.

The root of Thalictrum filiolosum DC. (Ranunculaceae) is also used as a substitute and adulterant to C. teeta. Since the roots of the species of the genus Swertia resemble rhizomes / roots of this plant in appearance, they are adulterated with this species as per market survey report. Investigations on the distribution range, demography, ecology, cytology, reproductive biology and population genetic structure of C.teeta were carried out, it was found to be endemic to a small area, to occupy a very narrow habitat and to be highly dispersed with very small population sizes. Study demonstrates by Qin [4]. revealed that the current method of Coptis planting leads to forest destruction. Even with reforestation measures, it leads to the loss of biodiversity in the forest. One sustainable alternative to

Table 1: Physico-chemical status of soil sample. the current Coptis planting is to incorporate it into agroforestry system. Scientist observed that that bamboo and fruit trees can be incorporated into the planting of Coptis chinensis during its different growing stages.

This not only diversifies villagers' income sources, but also recovers the forest at the same time. Edaphic factors were found to have played a vital role in ecological preference, natural distribution and evolutionary divergence of the species Mukherjee, et al. [5]. The species exhibits a ' $K$ ' strategy, high male sterility, low reproductive success and efficiency, inadequate seed dispersal, and little genetic variability. A combination of these genetic hurdles and external threats in the form of habitat disturbance and over-exploitation for commercial purposes could result in its extinction. The species was found to have highly specific microsite requirements that cannot be met in other habitats. It is argued that in situ conservation measures would be the best strategy for the continued survival of this species and any other endangered plant species. For effective management of the species it is recommended that its habitat be declared a protected area with the active cooperation of local inhabitants including the sharing of benefits of conservation Pandit and Babu [6]. Keeping this aspect in mind we try to study plant behavior and cultivation aspect with objective to acclimatize and conserve this plant species in Darjeeling hills.

\section{Materials and Methods}

The present study was conducted from September, 2009 to August, 2012 under the aegis of Uttar Banga Krishi Viswavidyalay, Kalimpong, with a objective of characterization of new plant Coptis teeta in Darjeeling hills Our focus on present study was mostly confined to Lava (2200 m asl) hill of Darjeeling. The region receives plenty of rains ( $>2000 \mathrm{~mm}$ annual rainfall) and has a wide range of climates from tropical to sub-alpine. Initial soil status of present experiment area (Table 1) and soil collected from Arunanchal Pradesh (Dibang Vally) were analyzed following the standard procedure Jackson [7]. and Black [8]. We collected plant from different pockets, and try to develop base population in lava. From there we have selected fourteen lines which survive under ex-situ conservation of Darjeeling hill with the objective to conserve and restore its base population for future generation and research work. Observations were taken after one year of planting consecutively for two years, to know about its morphological and flowering pattern along with good agronomic practices under limited resource (Figures $1 \& 2$ ).

\begin{tabular}{|c|c|c|c|c|c|c|c|c|}
\hline $\mathbf{p H}$ & $\begin{array}{c}\text { ECE (inch/ } \\
\text { cm) }\end{array}$ & \multicolumn{3}{|c|}{ Available (kg/ha) } & Total N (\%) & $\begin{array}{c}\text { Organic C } \\
\text { (\%) }\end{array}$ & $\begin{array}{c}\text { Organic } \\
\text { matter (\%) }\end{array}$ & C/N ratio \\
\hline & & N & P205 & K20 & & & & \\
\hline 5.1 & 0.18 & 253.3 & 21.5 & 219.5 & 10.81 & 2.752 & 4.98 & 16.11 \\
\hline
\end{tabular}




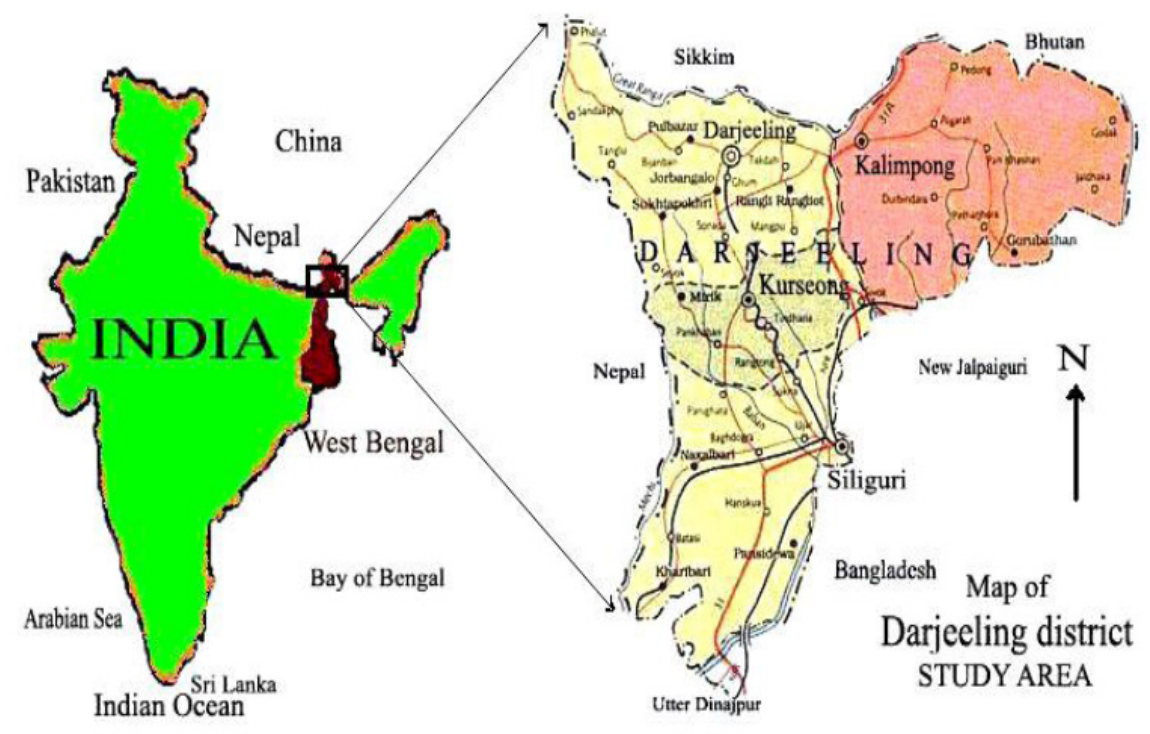

Figure 1: Location of Darjeeling district (study area) of West Bengal, India.

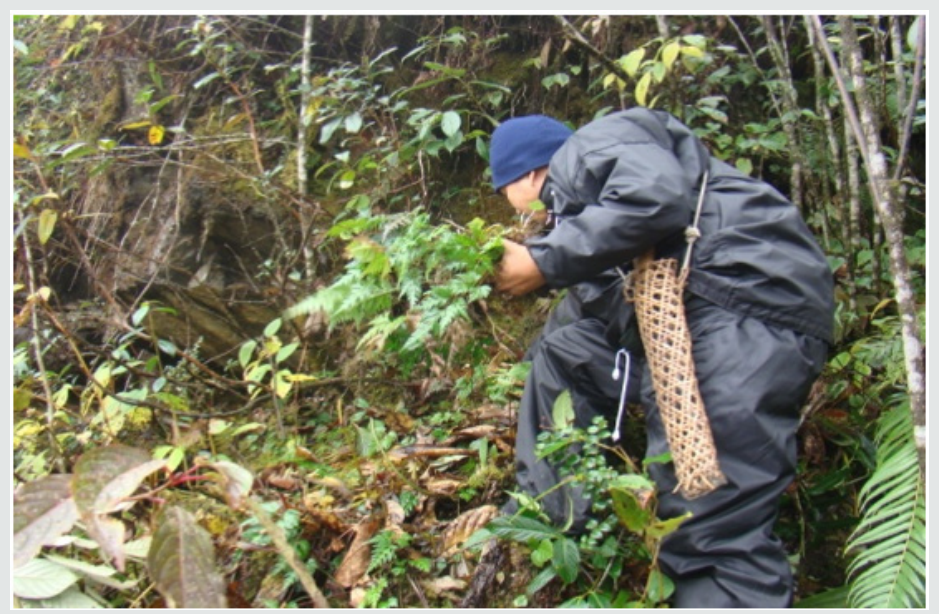

Figure 2: Collection of Coptis teeta plant by local growers.

\section{Result and Discussion}

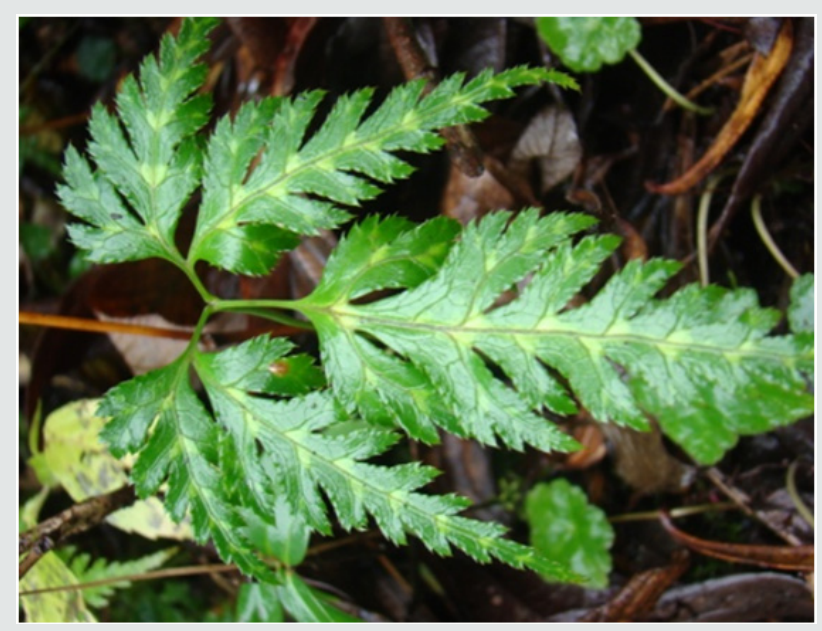

Figure 3: View of Coptis teeta. 
North eastern states namely Arunachal Pradesh, endowed with few of the valuable medicinal plants as per our survey during the 2009 to 2012, we found, Acorus calamus, Aquillaria agallocha, Berberis aristata, Bergia cilliata, Cinnamomum tamala, C. zeylanica, Coptis teeta, Cordiceps sinensis, Embelia ribes, Paris polyphylla, Rubia cordifolia, Gynocordia odorata, Illicium griffithii, Taxus wallichiana, Valeriana jatamansi and few notable species of Swertia chirayita. Plants belonging to Zingiberaceae like Curcuma aromatica, C. caesia, C. zedoaria, Hedychium coronerium, H. spicatum and Phyllanthus amaras were widely distributed in foot hills. Coptis teeta is one of the rarest plants on earth and mainly confined to Arunachal Pradesh, dibang and lohit vally. Presently, it is vulnerable in the wild Shankar and Rawat [9]. This plant grows in open forests in temperate regions and in moist soil. This grows in shady places in humus soil, and it belongs to RET species. A number of factors contribute to the endangerment of this plant species in the wild. In general medicinal plants are a valuable resource for regional economic development in the tropics and the Eastern Himalaya in particular which harbors many valuable plant species. Extensive deforestation and over-exploitation have brought several species to the brink of extinction, and Coptis teeta is such an endangered species; yet scientific information for its conservation is lacking. Further, the reproductive success of this herb is slow (Figures 3 \& 4).

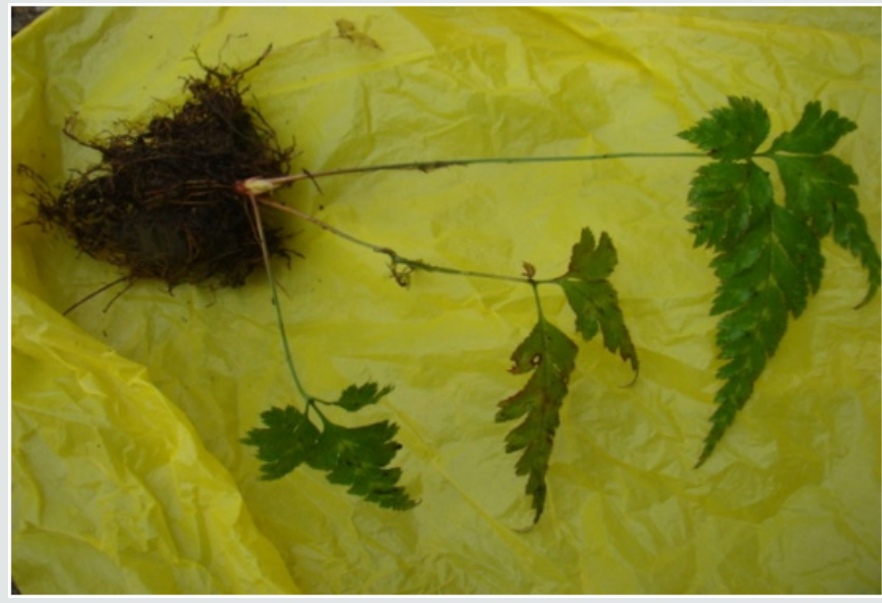

Figure 4: Plant with roots.

This plant prefer to grow in extreme part of north eastern state of Arunanchal Pradesh (Dibang Valley and Lohit districts) climate, as per our observation revealed that, very complex, because of the extreme differences in elevation. Topography, aspect and the location of the area, also have a substantial effect upon the local climate. Therefore, within short distances climates from subtropical to cold temperate can be experienced. These zones can be further modified by rain shadows, as in the leeward side of the high Himalaya mountain ranges. This plant does not grow in all types of climate and soil. It does well in temperate areas covered with snow during winter. It prefers well drained peaty sandy loam soil. Our observation of soil sample collected from this site revealed taht, the soil was sandy loam in texture, high in organic carbon (0.73 to 1.03 \%), available $\mathrm{N}$ (231.95 to $299.16 \mathrm{~kg} / \mathrm{ha}$ ), $\mathrm{P}_{2} \mathrm{O}_{5}$ (17.11 to $22.11 \mathrm{~kg}$ / ha) and $\mathrm{K}_{2} \mathrm{O}$ (186.19 to $273.11 \mathrm{~kg} / \mathrm{ha}$ ) content with $\mathrm{pH} 4.5$ to 5.6 . Our work in lava field particularly on characterization of this plant was done on the basis of phenotypical characters found which may vary in different environmental conditions, and according to the collection of this plant from different regions of Arunanchal Pradesh during September, 2009 different lines may be developed after establishing the base population in Lava field. After introduction in West Bengal hills (Lava) and domestication process for one year, many morphological variations were observed (Figures 5 \& 6). This was a small, stemless perennial evergreen herbs. Rhizome oblique to horizontal with persistent fibrous roots, bitter, yellowish brown externally, golden-yellow internally. Plant height vary from 10 to 18 $\mathrm{cm}$. Petiole length vary from 7 to $14 \mathrm{~cm}$, and its depend on growing condition of plant.

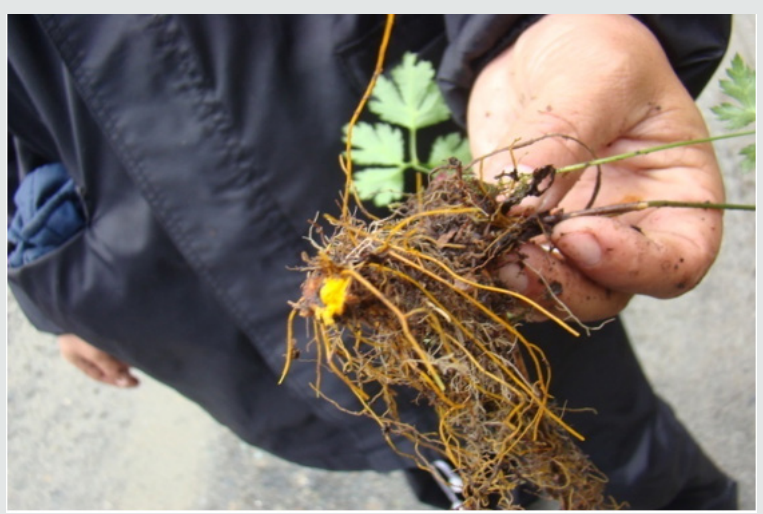

Figure 5: Plant with Rhizome. 


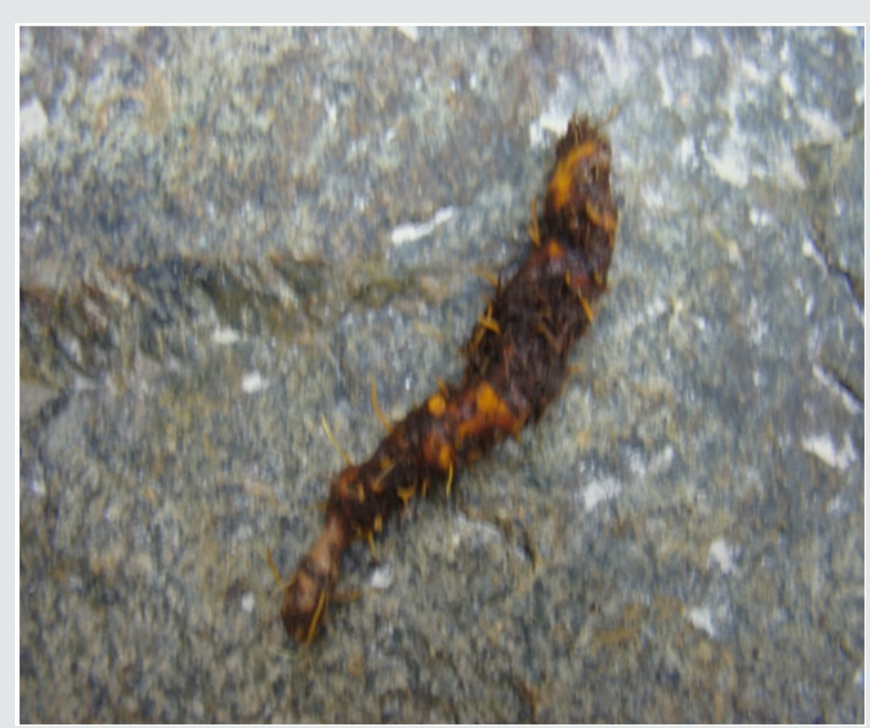

Figure 6: Fully Mature Rhizome.

Rhizome length vary from 2.1 to $4.9 \mathrm{~cm}$ depend on duration of crop. Rhizome weights vary from 4.3 to $8.9 \mathrm{~cm}$ (Table 2). Leaves 4.5-9.3 cm long lamina 3-lobed, pinnatifid, glabrous; Inflorescence panicled; flowers small, minimum one to few- flowered, white or yellowish. Fruit a follicle, many seeded. Seeds was black to dark brown in colour. Flower initiation and flowering period confined to mid of February to April, however it vary with land topographical situation. Rhizome was economical part of this plant, and its production start from six month onwards of transplanting. Rhizome of this plant is enormously used in Ayurveda, Siddha and Unani medicine. It is propagated by rhizomes and seeds. Viability of the seeds of this plant is short as per different literature. It can be raised through nursery beds, which can be prepared with two parts of soil rich in leafy mould and one part of sandy soil. As per our work in Lava (Darjeeling hills), 1:2:1 (Soil: Sand: forest manure) found to be favorable for its growth and development. Seeds can be dispersed over nursery bed from May to September. It germinates in 35 - 55 days. This was a slow growing herb. The seedlings can be transplanted in the field after ten month at a minimum spacing of 22.5 x $22.5 \mathrm{~cm}$ during April - May. However spacing 30 x $30 \mathrm{~cm}$ was found to be best, as per general observation. If the soil is hard, rhizome will not develop well. Since, the plant is generally cultivated in moist area, watering is not required. Collection of rhizomes is done from September onwards before snow fall. The rhizomes are dried in the Sun for a week and then sold in the market. Well-dried rhizomes can be stored and used for a maximum of eighteen years. The root is harvested in the autumn and can be used fresh or dried (Figure 7).

Table 2: Morphological characters of Coptis teeta plants in Darjeeling hills (Pooled data of two years).

\begin{tabular}{|c|c|c|c|c|c|c|c|c|c|c|c|}
\hline $\begin{array}{l}\text { No. of } \\
\text { selected } \\
\text { line. }\end{array}$ & $\begin{array}{c}\text { Plant } \\
\text { height } \\
\text { (cm) }\end{array}$ & $\begin{array}{l}\text { Leaf length } \\
\text { (cm) } \\
\text { (compound } \\
\text { leaf) }\end{array}$ & $\begin{array}{l}\text { Leaf breath } \\
\text { (cm) }\end{array}$ & $\begin{array}{c}\text { No of } \\
\text { leaves/ } \\
\text { plant }\end{array}$ & $\begin{array}{c}\text { Petiole } \\
\text { length } \\
(\mathrm{cm})\end{array}$ & $\begin{array}{l}\text { No. of } \\
\text { flowers/ } \\
\text { plant }\end{array}$ & $\begin{array}{c}\text { No of } \\
\text { fruits/ } \\
\text { plant } \\
\text { (follicle) }\end{array}$ & $\begin{array}{l}\text { Rhizome } \\
\text { girth cm }\end{array}$ & $\begin{array}{c}\text { Rhizome } \\
\text { length } \\
\text { cm }\end{array}$ & $\begin{array}{l}\text { Rhizome } \\
\text { wt gm }\end{array}$ & $\begin{array}{c}\text { Root } \\
\text { length } \\
\text { (Fibrous } \\
\text { root) cm }\end{array}$ \\
\hline 1. & 15 & $4.5-7$ & $5.6-6.2$ & 6 & $8-10$ & 4 & 3 & 1.5 & 2.6 & 1.89 & 4.3 \\
\hline 2. & 13.5 & $7.5-9.2$ & $3.5-4.2$ & 7 & $7.5-9$ & 3 & 3 & 1.7 & 2.8 & 2.1 & 5.6 \\
\hline 3. & 10 & $5-9$ & $3.5-4.5$ & 5 & 8-10.5 & 2 & 2 & 2.0 & 2.3 & 2.4 & 5.8 \\
\hline 4. & 14 & $6.5-8$ & $5-6$ & 11 & $7-10$ & 5 & 4 & 1.8 & 3.6 & 2.6 & 4.9 \\
\hline 5. & 15 & $6-7.8$ & $5.5-6.5$ & 5 & 7-7.5 & 4 & 2 & 2.5 & 3.9 & 3.5 & 6.9 \\
\hline 6. & 10 & $6-8$ & $3-3.5$ & 10 & 8-10 & 3 & 2 & 2.1 & 3.8 & 4.1 & 5.2 \\
\hline 7. & 18 & $7.5-9.5$ & $3.8-4.5$ & 14 & $12-14$ & 3 & 3 & 1.6 & 2.1 & 1.9 & 6.7 \\
\hline 8. & 17 & 8-8.6 & $4.5-5.8$ & 10 & $13-15$ & 5 & 5 & 2.3 & 2.8 & 2.8 & 8.9 \\
\hline 9. & 14.5 & 7.9-8.9 & $4.1-5.4$ & 8 & $10-13$ & 4 & 4 & 2.2 & 2.9 & 3.6 & 6.9 \\
\hline 10. & 18 & $5.7-7.5$ & $3.7-4.8$ & 6 & $11-15$ & 5 & 5 & 2.5 & 3.9 & 4.7 & 7.2 \\
\hline 11. & 15 & 6.8-8.1 & $3.7-4.6$ & 7 & $9-12$ & 4 & 3 & 2.7 & 4.9 & 4.9 & 7.8 \\
\hline 12. & 15.8 & $6.9-7.6$ & $2.1-3.8$ & 8 & $9-11$ & 4 & 3 & 2.4 & 4.6 & 4.3 & 6.7 \\
\hline 13. & 14.9 & $5.6-6.2$ & $3.5-4.8$ & 9 & $7.8-9$ & 5 & 4 & 2.3 & 3.5 & 3.6 & 6.8 \\
\hline 14. & 17.9 & $8.5-9.3$ & $3.6-4.3$ & 7 & $10-12$ & 4 & 4 & 2.6 & 2.7 & 4.2 & 5.8 \\
\hline
\end{tabular}




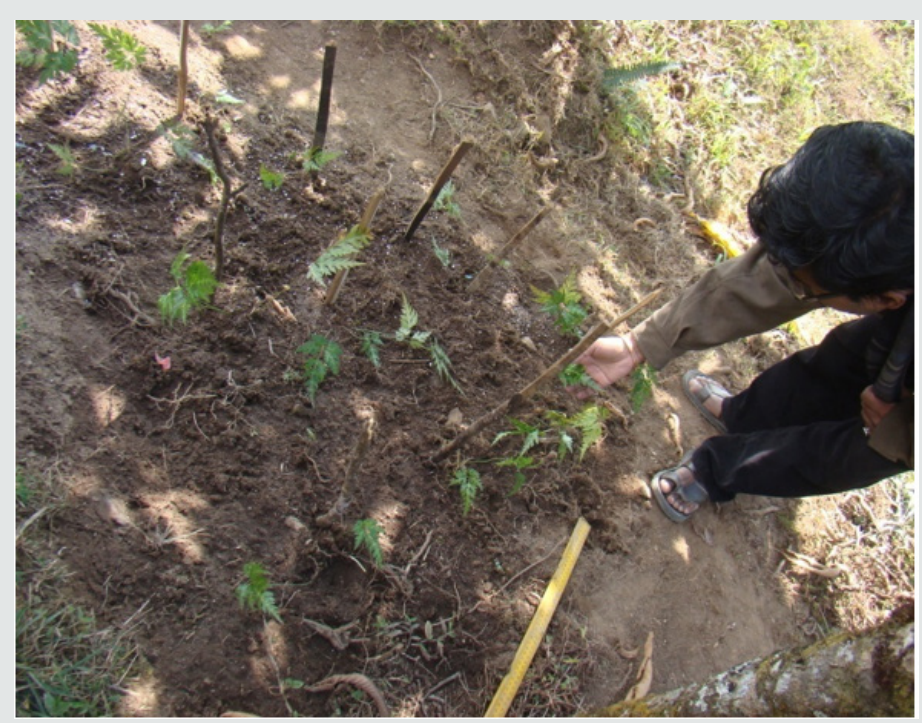

Figure 7: Acclimatization of Coptis teeta in Darjeeling hill (Lava, Kalimpong Block II).

As per discussion with forest and range officer, we came to know following few vital reasons for depletion of Coptis teeta in north Eastern Himalaya:

a. Increasing demand of herbal products, i.e., medicine as well as cosmetic has resulted very high demand of raw plant parts causing tremendous pressure on their natural habitat.

b. Shrinking of natural habitat of this rare plant due to population pressure and other developmental activities in hills.

c. Indiscriminate and over exploitation from natural sources.

d. Lack of agro-technology of highly demanded Coptis teeta plants, so farmer fears to adapt it in field condition.

e. No serious efforts for commercial scale cultivation.

f. Forest fire by local hill people to clear the land, plays a very devastating role in the destruction of this plants.

g. Illegal trading of banned high value medicinal plants.

h. Excessive grazing by domestic as well as wild animals.

i. Cutting of medicinal trees for fuel, timber, etc., and lopping of leaves for fodder and cattle bedding.

j. Change in climate and weather pattern.

k. Lack of awareness towards this valuable heritage.

\section{References}

1. Chakraborty S, Mukherjee D, Baskey S (2015) Paradigm of demographic stochasticity way to extinction of Valeriana jatamansi Jones, a valuable medicinal plant in North Eastern Himalaya region. Ecology, Environment and Conservation 21(1): 521-528.

2. Mukherjee D (2016) Soil and land management practices for saving hilly soil of Eastern Himalaya. The Himalayan Review 1(2): 356-366.

3. Huang J, Long C (2013) Coptis teeta-based agroforestry system and Its conservation potential: A Case Study from Northwest Yunnan. Field Crop Research, Springer 36(4): 343-349.

4. Qin Y (2010) Finding a sustainable way for Coptis chinensis cultivation in China. World Journal of Agricultural Sciences 6(4): 457-459.

5. Mukherjee D, Chakraborty S, Baskey S, Ali S (2014) Studies on effect of time of sowing and crop geometry on growth and economic yield of Valeriana jatamansi. Himalayan Research Journal 2(1): 80-86.

6. Pandit MK, Babu R (1998) Biology and conservation of Coptis teeta Wall. - an endemic and endangered medicinal herb of Eastern Himalaya. Environmental conservation 25(3): 262-272.

7. Jackson ML (1973) Soil Chemical Analysis, Prentice Hall of India Pvt. Ltd. New Delhi, India, pp 183-204.

8. Black CA, Evans DD, White JL (1965) Ensminger LE and Clark FE (eds) Methods of Soil Analysis", Part I- Physical and Mineralogical Properties, Including Statistics of Measurement and Sampling. American Society of Agronomy P 677.

9. Shankar R, Rawat MS (2013) Conservation and cultivation of threatened and high valued medicinal plants in North East India. International Journal of Biodiversity and Conservation 5(9): 584-591. 
(C) ()

This work is licensed under Creative

Commons Attribution 4.0 License

To Submit Your Article Click Here: Submit Article

DOI: 10.32474/CIACR.2019.06.000244

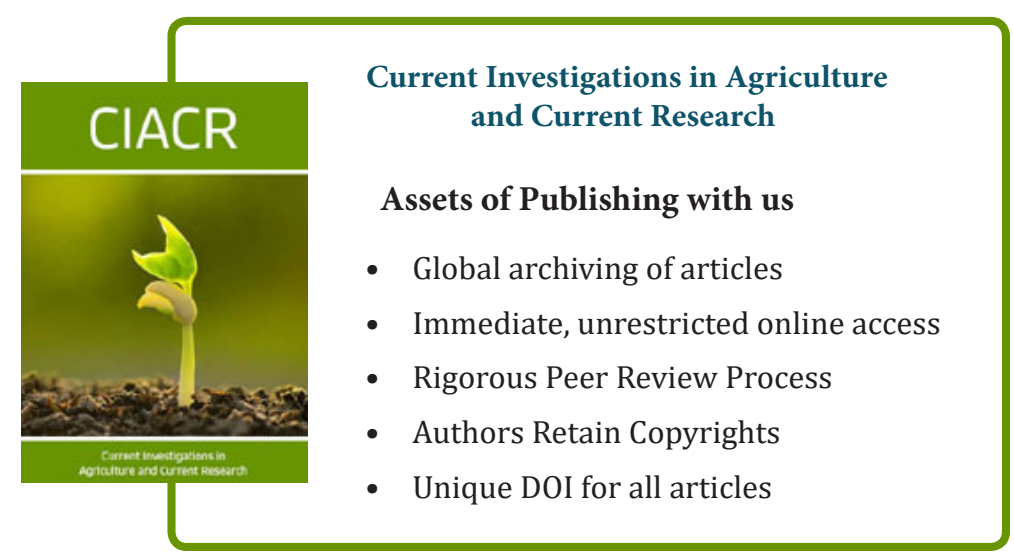

